\title{
Latest development of cloud computing technology, characteristics, challenge, services \& applications
}

\author{
Sushil kumar Choudhary ${ }^{1}$, R.S Jadoun ${ }^{2}$, H.L. Mandoriya ${ }^{3}$, Ashok Kumar ${ }^{4}$ \\ ${ }^{I}$ Research Scholar, Industrial \& Production Engineering, College of Technology, G.B.Pant University of \\ Agriculture \& Technology Pantnagar-263145, INDIA \\ ${ }^{2}$ Professor, Industrial \& Production Engineering, College of Technology, G.B.Pant University of Agriculture \& \\ Technology Pantnagar-263145, INDIA \\ ${ }^{3}$ Professor, Information Technology, College of Technology, G.B.Pant University of Agriculture \& Technology \\ Pantnagar-263145, INDIA \\ ${ }^{4}$ Assistant Professor, Information Technology, College of Technology, G.B.Pant University of Agriculture \& \\ Technology Pantnagar-263145, INDIA
}

\begin{abstract}
Cloud computing is a network-based environment that focuses on sharing computations, Cloud computing networks access to a shared pool of configurable networks, servers, storage, service, applications \& other important Computing resources. In modern era of Information Technology, the accesses to all information about the important activities of the related fields. In this paper discuss the advantages, disadvantages, characteristics, challenge, deployment model, cloud service model, cloud service provider \& various applications areas of cloud computing such as small \& large scale (manufacturing, automation, television, broadcast, constructions industries), Geographical Information system (GIS), Military intelligence fusion (MIS), business management, banking, Education, healthcare, Agriculture sector, E-Governance, project planning, cloud computing in family etc.
\end{abstract}

Keywords: Cloud computing, community model, hybrid model, Public model, private model

\section{1 Introduction}

\section{Introduction Of Cloud Computing}

Nowadays, with the rapid growth of cloud computing, many industries are going to move their computing activities to clouds. Cloud computing is the provision of computer or IT infrastructure through the Internet. That is the provisioning of shared resources, software, applications and services over the internet to meet the elastic demand of the customer with minimum effort or interaction with the service provider. It is a model for enabling ubiquitous, convenient, on-demand network access to a shared pool of computing resources (e.g., networks, servers, storage, applications, and services) that can be rapidly provisioned and released with minimal management effort or service provider interaction.

The cloud computing-based high-performance computing center aims to solve the following problems:

- High-performance computing platform generated dynamically

- Virtualized computing resources

- High-performance computer management technology combined with tradition ones

- High-performance computing platform generated dynamically

Different phase of cloud computing description table-1 \& showing figure- 2 .

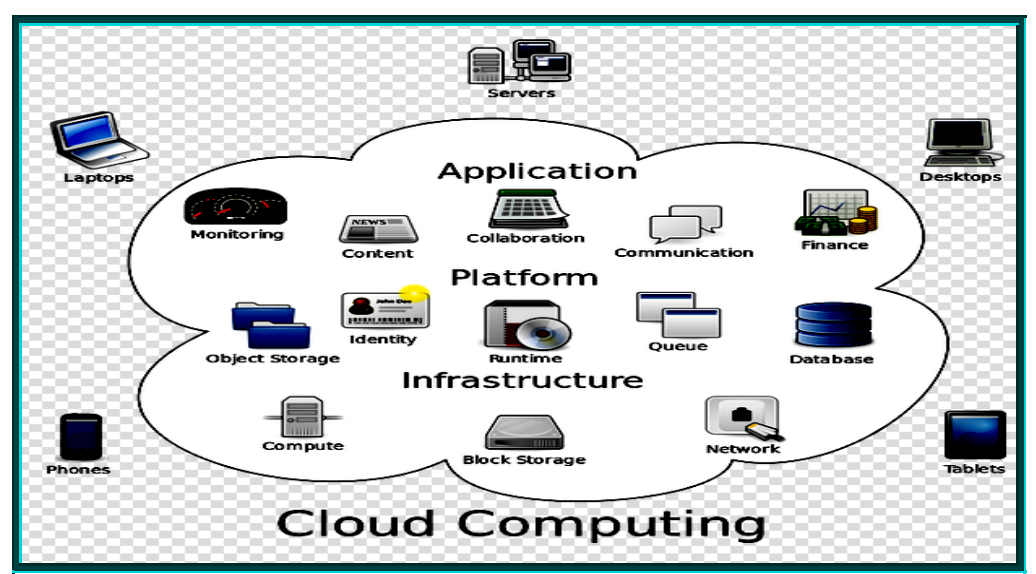

Fig.1 Cloud computing 
Latest development of cloud computing technology, characteristics, challenge, services \&

Table-1 Different phases of cloud computing

\begin{tabular}{|l|ll|}
\hline Phase & Description \\
\hline $\begin{array}{l}\text { 1. Mainframes } \\
\text { 1950s }\end{array}$ & - & $\begin{array}{l}\text { Users shared powerful mainframes using dummy terminals. } \\
\text { Start of automation phase } \\
\text { Localized Infrastructure }\end{array}$ \\
\hline $\begin{array}{l}\text { 3. Network } \\
\text { Computing }\end{array}$ & - & $\begin{array}{l}\text { Stand-alone PCs became powerful enough to meet the majority of users needs. } \\
\text { Rise in Demand of personnel Computer } \\
\text { Decentralized Computing } \\
\text { Birth of IT service }\end{array}$ \\
\hline $\begin{array}{l}\text { 4. Internet } \\
\text { 200mputing }\end{array}$ & - & $\begin{array}{l}\text { PCs, laptops and servers were connected together through local networks to share } \\
\text { resources and increase performance. }\end{array}$ \\
\hline $\begin{array}{l}\text { 5. Grid computing } \\
\text { Beyond 2010 }\end{array}$ & - $\begin{array}{l}\text { Local networks were connected to other local networks forming a global network } \\
\text { such as the Internet to utilize remote applications and resources. }\end{array}$ \\
\hline $\begin{array}{l}\text { 6. Cloud } \\
\text { Computing } \\
\text { Beyond 2010 }\end{array}$ & - $\begin{array}{l}\text { Computing provided shared computing power and storage through a distributed } \\
\text { Solving large problems with parallel computing }\end{array}$ \\
\hline
\end{tabular}

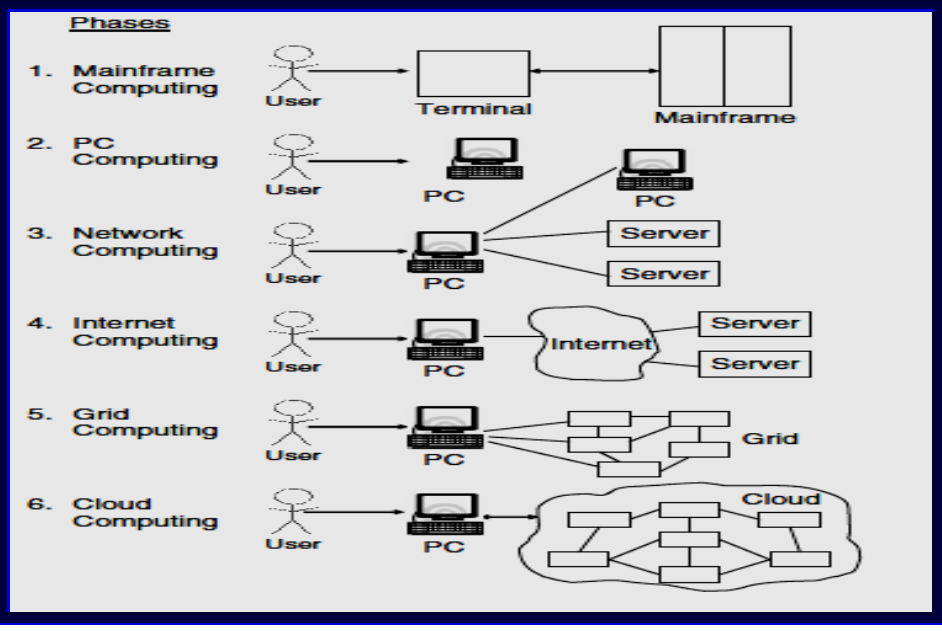

Fig.2 Evolution of cloud computing

Table-2 Advantages \& Disadvantages of Cloud computing

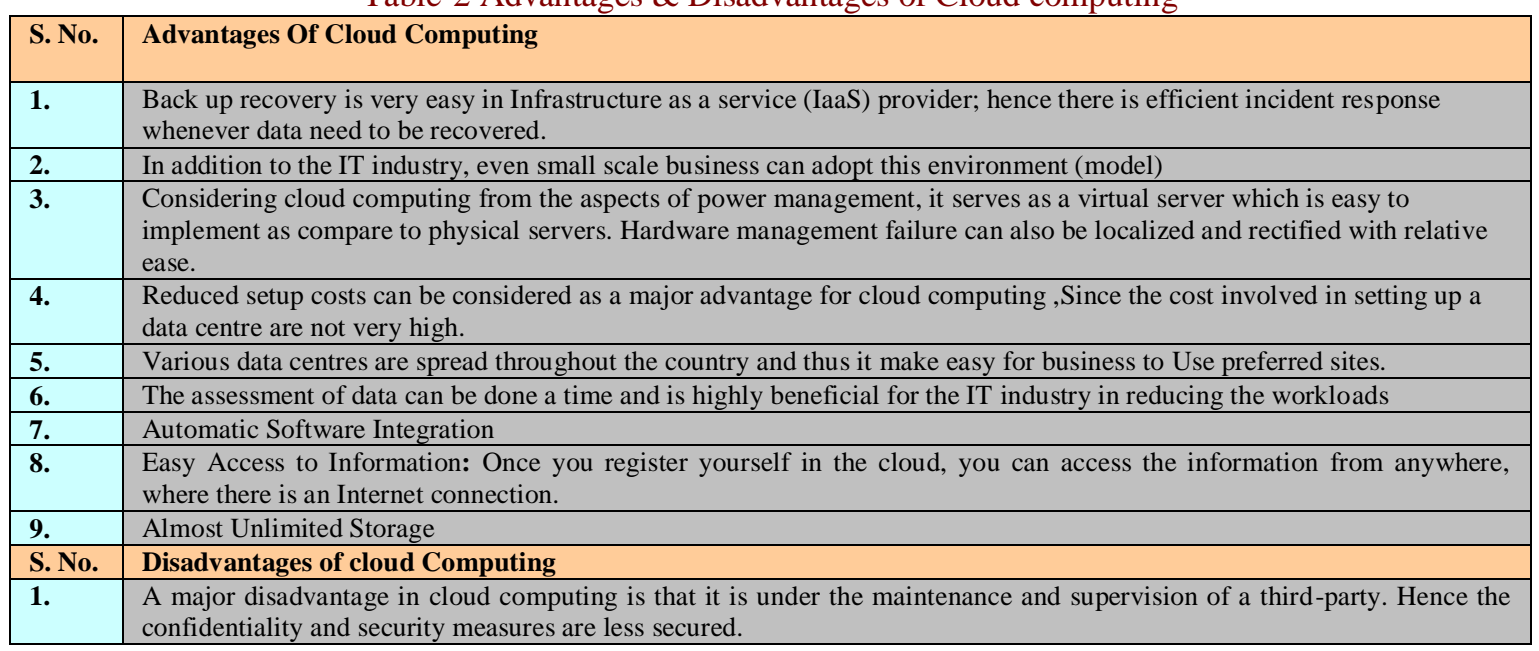




\begin{tabular}{|l|l|}
\hline 2. & $\begin{array}{l}\text { In cloud environment the data is not specifically segregated. It is distributed throughout the cloud network and causes the } \\
\text { problems when specific data needs to be segregated. }\end{array}$ \\
\hline $\mathbf{3 .}$ & $\begin{array}{l}\text { The Quality of service is a key determining factor in the efficiency of a cloud network. A reliable service provider } \\
\text { providing desired quality of service may be difficult to source and the process set-up could turn out to be time consuming. }\end{array}$ \\
\hline $\mathbf{4 .}$ & $\begin{array}{l}\text { Another major drawback is the dependence on network connectivity .Network failure can result in loss to the company by } \\
\text { causing extensive time delays }\end{array}$ \\
\hline $\mathbf{5 .}$ & $\begin{array}{l}\text { Storing information in the cloud could make your company vulnerable to external hack attacks and threats. As you are } \\
\text { well aware, nothing on the Internet is completely secure and hence, there is always the lurking possibility of stealth of } \\
\text { sensitive data. }\end{array}$ \\
\hline
\end{tabular}

\subsection{Cloud Computing Characteristics}

1. On-demand self-service: A consumer can unilaterally provision computing capabilities, such as server time and network storage, as needed automatically without requiring human interaction with each service provider.

2. Broad network access: Capabilities are available over the network \& accessed through standard mechanisms that promote use by heterogeneous thin or thick client platforms (e.g., mobile phones, tablets, laptops, and workstations).

3. Rapid elasticity: Cloud services can be rapidly and elastically provisioned, in some cases automatically, to quickly scale out and rapidly released to quickly scale in. To the consumer, the capabilities available for provisioning often appear to be unlimited and can be purchased in any quantity at any time.

4. Measured service: Pay per use-capabilities is charged using a metered, fee-for-service, or advertising based billing model to promote optimization of resource use. Examples are measuring the storage, bandwidth, \& computing resources consumed and charging for the number of active user accounts per month.

5. Resource pooling: The provider's computing resources are pooled to serve multiple consumers using a multi-tenant model, with different physical and virtual resources dynamically assigned and reassigned according to consumer demand. There is a sense of location independence in that the customer generally has no control or knowledge over the exact location of the provided resources but may be able to specify location at a higher level of virtuality (e.g., country, state, or data center). Examples of resources include storage, processing, memory, network bandwidth, and virtual machines.

\subsection{Cloud computing Challenge}

1. Indirect administrator accountability

2. Need for isolation management

3. Logging challenges

4. Quality of service guarantees

5. Dependence on secure hyper visors

6. Attraction to hackers (high value target)

7. Data ownerships issues

8. Encryptions needs for cloud computing

9. Less of physical control

10. data dispersal \& International privacy Law

\section{Deployment Model Of Cloud Computing}

Cloud computing can be deployed in four different ways: private cloud, public cloud, community cloud, hybrid cloud - combination of both public and private.

\subsection{Private cloud}

The private cloud represents a model where a single organizations stand up cloud capacity and only the member of organizations are allowed to consume the capacity. This is a common model for government and large enterprise private cloud is good in security concern; it may exit on premise or off premise. Example- eBay

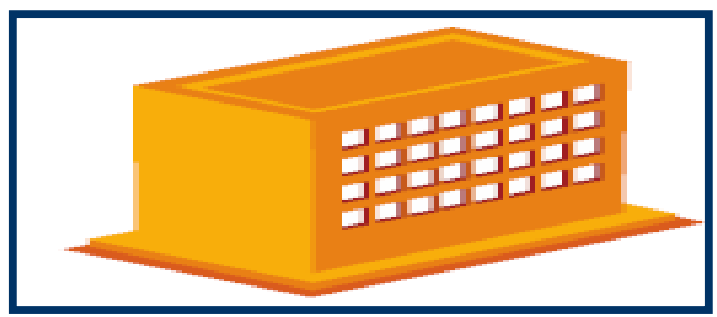

Fig. 3 private Cloud 


\subsection{Public (General) clouds}

The cloud infrastructure is available to general public. It's a cloud that anyone can use like google, amason Public cloud implementation are large cloud implementations around.

Example: Amazon, Google Apps, Windows Azure.

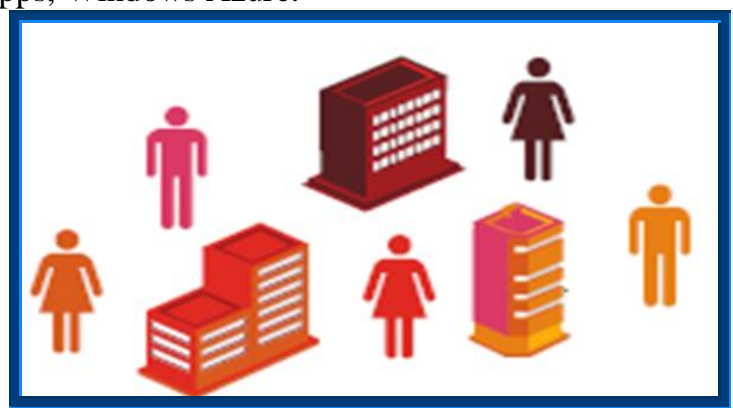

Fig. 4 Public Cloud

\subsection{Community (domain specific) clouds}

These clouds are maintained for specific requirements by a group of organizations. It is computing resources provided over the internet for restricted use by a specific community of users from organizations that have shared interest. Usually the users are a group of people with a common background or with shared concerns within the community or society. Community clouds are an intermediary between private and public clouds. It may be managed and operated by one or more of the organizations in the specific community, a third party, or some combination of them, and it may exist on or off premises.

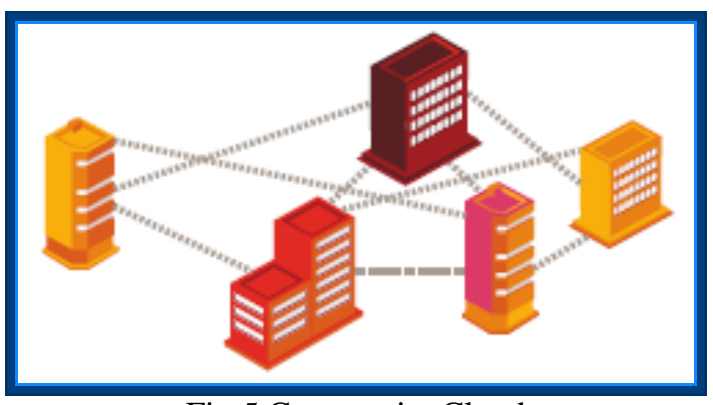

Fig.5 Community Cloud

\subsection{Hybrid cloud (Mixed model)}

The Hybrid cloud are combination of two or more cloud model (private, community, public) that remain unique entity but are bound together by standardized technology that enable data and application portability. Cloud infrastructures aimed at achieving ultimate cost reduction through outsourcing while maintaining the desired level of control. According Examples: Google, Amazon, Windows Azure

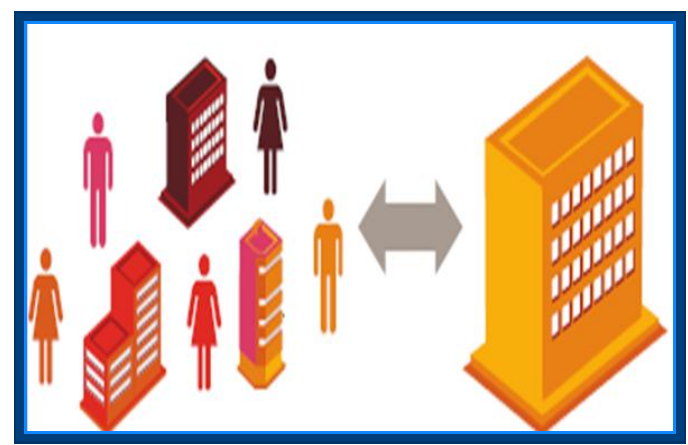

Fig.6 Hybrid Cloud

\section{Cloud Service Model}

A cloud based architecture can be defined as a set of resources - hardware and software, which combine together to deliver the aspects of computing as a service. Services in such a scenario are charged on a usage based pricing model and the users are no longer required to care about the intricacies which are needed to be taken care in a traditional on-premise computing model. 


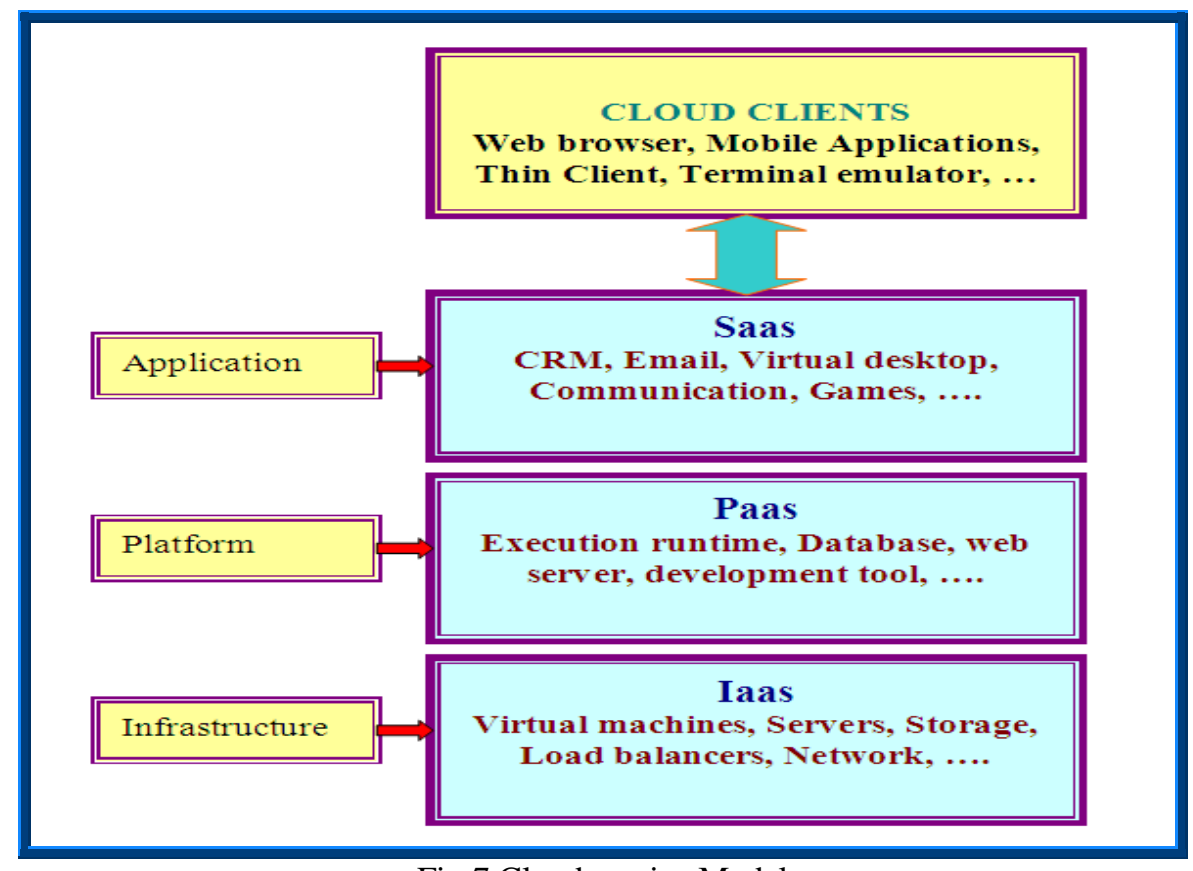

Fig.7 Cloud service Model

3.1 IaaS (Infrastructure as a service) model: In an IaaS model, resources can easily be scaled up, depending upon the demand from the user, services being charged in a pay-per use model. The main concept behind this model is virtualization where user have virtual desktop and consumes the resources like network, storage, virtualized servers, routers and so on, supplied by cloud service provider. Usage fees are calculated per CPU hour, data GB stored per hour, network bandwidth consumed, network infrastructure used per hour, value added services used, e.g., monitoring, auto-scaling etc. Examples: Storage services provided by Amazon S3, Amazon EBS. Computation services: AmazonEC2, Layered tech and so on.

\subsubsection{Application Security Policy Considerations}

- The consumer has responsibility for deployment of the complete software stack Operating system, middleware and application and for all aspects of security that relate to this stack.

- The application security policy should closely mimic the policy of applications hosted internally by the consumer.

- The consumer should focus on network, physical environment, and auditing, authorization, and authentication considerations as outlined in this document.

- The consumer is typically responsible for patching of operating system, middleware and application.

- Appropriate data encryption standards should be applied.

3.2 PaaS (Platform as a service) model: It refers to the environment that provides the runtime environment, software deployment framework and component on pay to enable the direct deployment of application level assets or web applications. PaaS is a platform where software can be developed, tested and deployed. It means the entire life cycle of software can be operated on a PaS. This service model is dedicated to application developers, testers, deplorers \& administrators. Examples: Google App Engine (GAE), Microsoft Azure, IBM Smart Cloud, Amazon EC2, salesforce.com and jelastic.com etc.

\subsubsection{Application Security Policy Considerations}

- The consumer has responsibility for application deployment and for securing access to the application itself.

- The provider has responsibility for properly securing the infrastructure, operating system and middleware.

- The consumer should focus on audit, authorization, and authentication considerations as outlined in this document.

- Appropriate data encryption standards .should be applied.

- In a PaaS model, the consumer may or may not have knowledge of the format and location of their data. It is important that they are knowledgeable of how their data may be accessed by individuals with administrative access.

3.3 SaaS (Software as a service): Through this service delivery model end users consume the software application services directly over network according to on-demand basis. For example, Gmail is a SaaS 
where Google is the provider and we are consumers. Other well known examples of PaaS include billing services provided by Arial system, op source. Financial services: Concur, workday, Beam4d. Backup and recovery services: Jungle Disk, Zmanda cloud back up and so on.

\subsubsection{Saas Application Security Policy Considerations:}

Application tier security policy constraints are mostly the responsibility of the provider and are dependent upon terms in the contract and SLA. The consumer must ensure that these terms meet their confidentiality, integrity and availability requirements.

- Important to understand providers patching schedule controls of malware, and release cycle.

- Threshold policies help to identify unexpected spikes and reduction of user load on the application. Thresholds are based on resources, users and data requests.

- Typically, the consumer is only able to modify parameters of the application that have been exposed by the provider. These parameters are likely independent of application security configurations, however, the consumer should ensure that their configuration changes augment; not inhibit the provider's security model.

- The consumer should have knowledge of how their data is protected against administrative access by the provider. In a SaaS model, the consumer will likely not be aware of the location and format of the data storage.

- The consumer must understand the data encryption standards which are applied to data at rest and in motion.

\begin{tabular}{|c|c|c|c|}
\hline 1. Service category & $\begin{array}{l}\text { VM Rental, Online } \\
\text { Storage }\end{array}$ & $\begin{array}{l}\text { Online Operating Environment, } \\
\text { Online Database, Online Message } \\
\text { Queue }\end{array}$ & $\begin{array}{l}\text { Application and } \\
\text { Software Rental }\end{array}$ \\
\hline $\begin{array}{l}\text { 2. Service } \\
\text { Customization }\end{array}$ & Server Template & Logic Resource Template & Application Template \\
\hline $\begin{array}{l}\text { 3. Service Provisioning } \\
\text { Service accessing and } \\
\text { Using }\end{array}$ & $\begin{array}{l}\text { Automation Remote Console, } \\
\text { Web } 2.0\end{array}$ & $\begin{array}{l}\text { Automation Online Development \& } \\
\text { Debugging, Integration of Offline } \\
\text { Development Tools \& Cloud }\end{array}$ & $\begin{array}{l}\text { Automation } \\
\text { Web } 2.0\end{array}$ \\
\hline 4. Service monitoring & $\begin{array}{l}\text { Physical Resource } \\
\text { Monitoring }\end{array}$ & $\begin{array}{l}\text { Logic Resource } \\
\text { Monitoring }\end{array}$ & $\begin{array}{l}\text { Application } \\
\text { Monitoring }\end{array}$ \\
\hline $\begin{array}{l}\text { 5.Service level } \\
\text { management }\end{array}$ & $\begin{array}{l}\text { Dynamic Orchestration of } \\
\text { Physical Resources }\end{array}$ & $\begin{array}{l}\text { Dynamic Orchestration of } \\
\text { Logic Resources }\end{array}$ & $\begin{array}{l}\text { Dynamic Orchestration of } \\
\text { Application }\end{array}$ \\
\hline $\begin{array}{l}\text { 6. Service resource } \\
\text { optimization }\end{array}$ & $\begin{array}{l}\text { Network Virtualization, } \\
\text { Server Virtualization, } \\
\text { Storage Virtualization }\end{array}$ & $\begin{array}{l}\text { Large-scale Distributed File } \\
\text { System, Database, Middleware etc }\end{array}$ & Multi-tenancy \\
\hline 7. Service measurement & $\begin{array}{l}\text { Physical Resource } \\
\text { Metering }\end{array}$ & $\begin{array}{l}\text { Logic Resource Usage } \\
\text { Metering }\end{array}$ & $\begin{array}{l}\text { Business Resource } \\
\text { Usage Metering }\end{array}$ \\
\hline $\begin{array}{l}\text { 8. Service integration } \\
\text { and combination }\end{array}$ & Load Balance & SOA & SOA, Mashup \\
\hline 9. Service security & $\begin{array}{l}\text { Storage Encryption and } \\
\text { Isolation, } \\
\text { VM Isolation, VLAN, } \\
\text { SSL/SSH }\end{array}$ & $\begin{array}{l}\text { Data Isolation, Operating } \\
\text { Environment Isolation, } \\
\text { SSL }\end{array}$ & $\begin{array}{l}\text { Data Isolation, Operating } \\
\text { Environment Isolation, SSL, } \\
\text { Web Authentication and } \\
\text { Authorization }\end{array}$ \\
\hline
\end{tabular}

\section{Cloud Computing Service Providers}

The term "cloud computing" refers to accessing services or information from third party data centers remotely over the Internet from any location.

1. Amazon Elastic Compute Cloud (EC2) is a central part of Amazon.com's cloud computing platform, Amazon Web Services (AWS). EC2 allows users to rent virtual computers on which to run their own computer applications. EC2 allows scalable deployment of applications by providing a Web service through which a user can boot an Amazon Machine Image to create a virtual machine, which Amazon calls an "instance", containing any software desired. A user can create, launch, and terminate server instances as needed, paying by the hour for active servers, hence the term "elastic". EC2 provides users with control over the geographical location of instances that allows for latency optimization and high levels of redundancy

2. Google: Google offers Google App engine, which enables developers to build their own web application. The Google App engine provides a fully integrated application environment. It is used for delivering many different services to its users, including E-mail access, document applications, text translations, maps, web analytics etc.

3. Google App Engine: Google is a leader in web- based applications, This provides a fully integrated application environment using google development tool \& computing cloud, Google App engine applications are easy to build, easy to maintain, \& easy to scale. All you have to do is develop your 
application (using Google's APIs \& the Python Programming language ) \& upload it to the App Engine Cloud; from there, it's ready to serve your users. A free App Engine is completely free to use at basic level, anyway. A free App Engine account gets up to 500MB of storage \& enough CPU strength \& bandwidth for about 5 million page views a month. If you need more storage, power, capacity, Google intends to offer additional resource in the near future. It include the following features:

- Dynamic web serving

- Automatic scaling \& load balancing

- Full support for all common web technologies

- Persistent storage with queries, sorting \& transactions

- APIs for authenticating users \& sending email using Google accounts

4. Salesforce.com: Most popular web-based contact management/ Customer relationship management (CRM) today is offered by Salesforce.com (www.salesforce.com). In fact, the company offers several different cloud services: salesforce.com, a software-as-a-service (SaaS), CRM applications designed for sales marketing, customer Service \& others used force.com, platform-as-a-service (Paas) applications. The platform as a service is entirely on-demand, running across the internet. Salesforce provides its own Force.com.

5. Microsoft: Microsoft windows azure is based on cloud computing. Running applications and storing data on machines in data center accessed via the internet can provide a lot of advantages.

6. Amazon: Amazon is one of the largest retailors on the internet and also one of the primary providers of cloud development services. It is a commercial web service that allows developers and companies to rent capacity on Amazon"s propriety cloud of servers, which happens to be one of the biggest server farms in the world. Amazon's service lets customers choose from three sizes of virtual servers:

Small, which offers the equivalent of a system with $1.7 \mathrm{~GB}$ of memory, $160 \mathrm{~GB}$ of storage, and one virtual 32-bit core processor?

Large, which offers the equivalent of a system with $7.5 \mathrm{~GB}$ of memory, $850 \mathrm{~GB}$ of storage, \& two 64 bit virtual core processors

Extra large, which equivalent of a system with 15 GB of memory, 1.7 TB of storage, \& four virtual 64-bit core processors

EC2 is just part of Amazon's web Service (AWS) set of offering, which provides developers with direct access to Amazon's software \& machines.

7. 3tera (www.3tera.com), which offers the App logic grid operating system \& cloudware architecture for on-demand computing.

8. 10gen (www.10gen.com), which provides a platform for developers to build scalable web-based applications.

9. Mosso (www.mosso.com), which provides an enterprise-level cloud hosting service with automatic scaling.

10. Skytap (www.skytap.com), which provides the virtual lab on-demand web-based automation solution that enables developers to build \& configure lab environments using pre-configured virtual machines.

\section{Applications Of Cloud Computing}

Cloud computing system in nowadays various applications of manufacturing industries, automation, construction industries, geographical information system, business management, health sector, education, banking sector, agriculture sector etc.

\section{Cloud computing system in education}

Once any of the computer system connected with internet gets started then it will directed the student, teacher or in better words a whole institute to the cloud. In cloud both the students and teachers have to login with their separate id and from here the first best feature that is to monitor attendance of teacher and student is possible, secondly Live and recorded both type of the lectures can be seen by the student. The best part of this facility is that a student studying at any school and another student studying at any big name school both are attending the same tutorial from a highly skilled faculty at the same time. Thirdly entire examination process is changed and now the exams will be conducted on cloud and the results of each and every exam that is even a class test is reported directly to the concerned authority. With this new system parents can be able to monitor their ward attendance and his growth in the session. This new system also helps the students to prepare well for the upcoming competitive exams like NTSE, IIT JEE, AIEEE, PET, and PMT etc and stop the fashion of joining big coaching and spending their parents hard earned income. Main Advantages of Cloud computing in Education are listed in the below

- Teleconferencing \& Distance learning

- hybrid classes (online \& off-campus learning) 
- Acquiring and implementing the latest software and application updates.

- Streamlining enrollment and admissions processes that are costly and time-consuming.

- Offering schools, colleges, universities and others a low cost option for using high concept computing systems. All that's needed is an internet connection which is low cost.

- Sharing work without having to use paper. Using paper is costly both to the environment and in monetary terms and is therefore no longer a viable way to educate.

- Removing the admin burden allows educational facilities to concentrate on their core business and be more productive .IT admin including licensing issues, software updates and IT security management will all be taken care of by Cloud provider.

- Storing confidential and critical data centrally in the cloud, which is less prone to exposure threats such as the loss or theft of laptops or USB flash drives.

- Allowing free access applications and Updating stock of information.

- Higher quality of education delivered anytime anywhere: Courses with updated content can b delivered consistently across all locations.

- Leveraging on limited staff or teachers, a university can reach out to numerous students all across the globe, hence limiting the costs of education delivery.

- Scalable systems on cloud to provision big data platform for research and analysis.

- Courses delivered over cloud through a central location will lead to a standard content delivery to multiple remote virtual classrooms.

- Students and teachers can collaborate on studies, projects using collaboration solutions.

\section{Cloud computing in healthcare}

The healthcare industry has been leveraging technological innovations for decades to provide superior quality services to patients. Medical technology-based devices and equipments such as Computed Tomography (CT) Scanners, Diagnostic Sonographic Scanners, Magnetic Resonance Imaging (MRI) Scanner, remote monitoring devices, health and wellness-check devices etc. have helped in diagnosing health problems eliminating the need of expensive and hazardous surgeries. In healthcare provisioning process, once the patient is admitted into the hospital and his details are entered in the Hospital Management Information System (HMIS) the process of diagnosis begins. Now let us consider scenario when doctors are standing in demand side, he wants to access information about patient from Hospital Management Information System. Doctor will consult to admin of HMIS and admin will reply with complete information about patient. In the process, the doctor might take expert advice as and when required. And cloud expert will reply with expert advice. Cloud computing technologies allow the remote monitoring of a patient's Heartbeat data, its analysis in minimum time, and the notification of first-aid personnel. This way a patient at risk can be constantly monitored without going to hospital. Most important advantages of cloud computing in healthcare

- Online health monitoring system hosted in the cloud

- Patient care can be improved by providing this service through the cloud faster and more efficiently

- The cloud offers providers the ability to access specific experts to manage and maintain their systems

- Healthcare providers are in the business of treating and caring for patients.

- Health information Exchange (HIE) between the physicians, hospitals \& other health care organization

- The evaluation \& Adoption of Technologies that allow physician to remotely visit patient via video conference.

- A clinical Information System (CIS) allows healthcare providers to schedule \& order lab test, quickly access test results, send prescription directly to the pharmacy \& manage all the critical notes from the doctors \& specialists without unnecessary double data entry.

- Health care data security is improved.

- Electronic Medical Records (EMR): Hospitals \& physicians are starting to see cloud based medical records $\&$ medical images achieving services coming on line.

- Telemedicine has grown to include not only tele-consultations \& tele surgeries, but also health record Exchange, Video-Conferencing \& home monitoring.

\section{Manufacturing and Automation}

The Cloud could increase productivity, quality, efficiency, flexibility, and versatility of almost all automation systems. Below is a list of potential benefits:

\section{A. Allow manufacturing and automation as services over the cloud}

- Facilitate small shops bidding on jobs and also let shops rent out idle equipment

- Reduce design and prototype time 
- Better connection to consumers and suppliers

B. Extremely flexible manufacturing

- Adaptive and reconfigurable manufacturing line for multiple products

- Fast response to market change

- Connection to database at both micro (i.e. production line status) and macro (social activities, news, weather, stock market, currency exchange, etc.) levels to allow proactive response to changes.

- Autonomous material recognition, handling and transportation

- Fault diagnosis and robustness to failure to reduce down time

C. Crowd sourcing

- Crowd assisted data analysis

- Provide knowledge for automation system to learn

- Collaborative design and verification

- Better access to a variety of intellectual resource for complex problems

D. Personalized and customized products

- Commodity vs branding, online user reviews and feedback systems enable small businesses to quickly establish themselves.

- Enabling new technologies such as 3D printing and mobile phones

- In medical markets, fashion items (e.g. shoes, eyeglasses)

E. Production capacity / resources sharing

- Higher utilization of the equipment

- Reduction of capital investment

- Easier management

F. Optimized complexity

- Better managing increased globalization and complexity

- Reduced impact on quality due to complex manufacturing network

G. Subscription-based pricing model which ensures that organizations pay only for the capacity that they require and for the time they need.

\section{Mechanical Engineering}

Mechanical design platform software in engineering Cloud that is used in Particular product development. This mechanical Design Platform software is based on virtual product software (VPS) technology. VPS technology allows the user to quickly \& easily use 3D data throughout data overall life cycle of the product. VPS has been provided to users inside \& outside the company \& received favorably as a user friendly tool that allows the Mechanical 3D data.

\section{GIS applications}

Geographic Information System (GIS) is used for taking high quality satellite photos. These photos have rising requirement. These high quality photos needed computational power and high quality data storage.

\section{Military intelligence fusion (MIF)}

MIF is the process of military intelligence data fusion. MIF as a process of adjusting, combining and incorporating the information and data from multi-source into a uniform expression to obtain accurate target position, state estimation, identity validation. Using cloud computing it offer dynamic accessing intelligence resource pool.

\section{Television and broadcast industry}

Cloud computing will become the core technologies in the tri-network integration and the next generation of broadcasting television network.

\section{Field of Power Engineering}

Moscow Power Engineering Institute (MPEI) makes an on-line calculation server for an engineer which is contains tables on specific volume, enthalpy, entropy, isobaric tension, dynamic viscosity, thermal conductivity etc. which is easily accessible on-line.

\section{Banking Sector}

Using of cloud computing in banking sector gets more beneficial compare to traditional network. Cloud computing provide centralized server for the employer and customer. Cloud computing sole the software 
problem to install in each computer for any application software and manage individual computer. Advantages of Cloud Computing in the banking sector listed in the below

- No need for heavy investments in new hardware and software.

- Cost saving \& usages-based billing

- Achieve higher level of data protection, disaster recovery \& fault tolerance

- Cloud is available on-demand; less infrastructure investments are required, saving initial set-up time.

\section{E-Governance}

E-Governance is a process of government work, share information \& deliver services to the client. Various types of E-Governance applications are as follows

- Government to Government (G2G): Various types of functions of the government interact to fulfill the work. Administration, inter governance enterprise and control monitor and distribution etc.

- Government to Enterprise (G2E): Enterprises like water board, electricity are controlled by the governments and should react quickly to government policies.

- Government to Business (G2B): Government interacts with various business activity such as collection of taxes, contract management etc.

- Government to Consumer (G2C): Government provides numerous services to their citizens.

\section{Construction Industry}

The construction industry balances back-office functions - billing, paying invoices, running financial reports, payroll, planning logistics - with the physical presence needed on the job site or in a client's office. Today's technological solutions must be able to serve users in both work settings. As a result, making missioncritical business applications available remotely is a hot topic these days. Remote access allows staff to work from any location without being tied to a specific physical location. With the amount of consolidation, decentralization of offices, travel-based positions, and project work being done in different regions of the country or even internationally, being able to offer solid remote access technology to employees is critical for a construction company's success. With web-based tools for time capture, project management, and service management for general contractors, subcontractors, and owners, Sage will deliver a comprehensive cloudbased solution to address the evolving construction management needs of our customers.

\section{Project Planning}

Project management is the act of planning, organizing, \& managing resource to bring about the successful completion of specific project objectives. Project participants involve different types of work \& different location. Naturally, a web-based application lets participants from different locations access the same master files. Users can access files from any internet-connected computer using any web browser.

\section{Agriculture sector}

Cloud computing applications of agriculture sector will play the following role:

- Agriculture information data bank (crop, weather, soil, growth progress, farmer data, expert consultation) it can be used to store all the agriculture related information in a centralized cloud, which will be available to all the users at anytime, anywhere

- High integration and sharing of agriculture information

- Providing agricultural technology service \& science

- Construction and improvement of the agricultural products supply chain

- Monitoring \& tracking of the agricultural products quality

- Efficient use of agricultural resources

- Promote the circulation of agricultural product

\section{Cloud computing in a family}

Cloud computing various role play in our family listed in the below

- Centralizing Email communication: it can be used cloud-based tools to help improve communications between family members.

- Collaborating on Schedule

- Collaboration on Grocery lists

- Collaboration on household budgets

- Collaboration on contact management

- Collaboration on school projects

- Sharing family digital photo 


\section{Conclusions}

Cloud computing is an emerging technology which can bring revolutionary changes in the usage of internet. Cloud computing is a combination of various computing technologies and it can play a major role in bringing significant improvement in data transfer and communication. This paper provides a basic understanding of cloud computing which includes the cloud model, types of clouds, services, issue \& applications. This paper also elaborates the recent trends in cloud computing. Future work aims at understanding the basic technologies involved in cloud and also to get an insight of various security and privacy issues associated with cloud. Summary of the in this paper identifies the following figure.

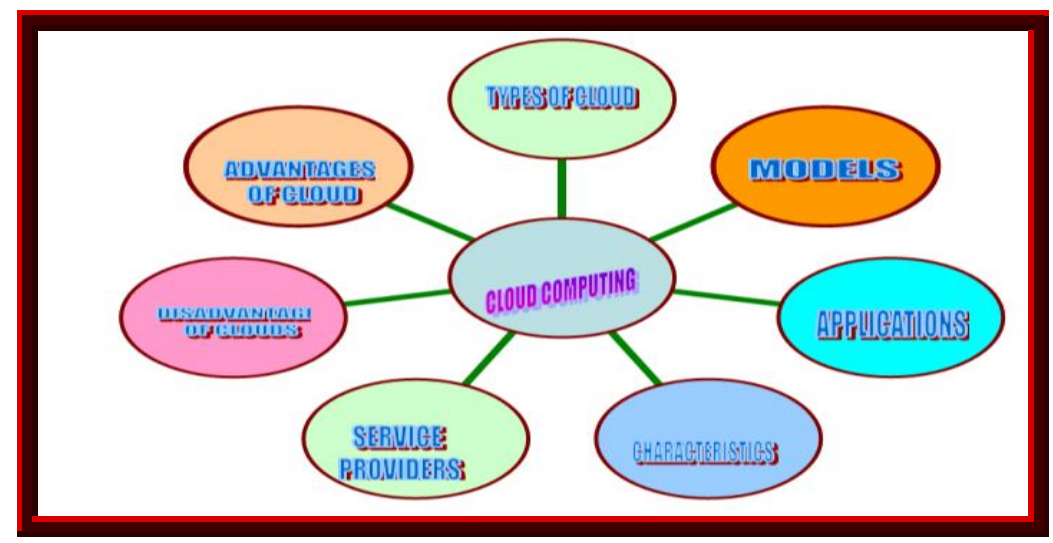

Fig. 8 cloud computing summary

VII. Future Research Areas

Although much progress has already been made in cloud computing, we believe there are a number of research areas that still need to be explored. Issues of security, reliability, and performance should be addressed to meet the specific requirements of different organizations, infrastructures, and functions.

- Data Security improvement

- Expand to small and medium sized companies applications

- Reliability

- Vulnerability to attacks

- Cluster distribution

- Network optimization

- Interoperability

\section{References}

[1]. Eviwiekpaefe, A.E. \& Ajakaiye,F., (2014), "The trend and challenges of cloud computing: a literature review", International Letters of Social and Humanistic Sciences5,pp.13-20

[2]. I. Foster, Y. Zhao, I. Raicu, and S. Lu, Cloud Computing and Grid Computing 360- Degree Compared, http://arxiv.org/abs/0901.0131[Accessed May 19, 2012].

[3]. S. Biswas, "Where Is Cloud Computing Going? Up, Up And Away!" January 25, 2011, http://www.cloudtweaks.com/2011/01/where is cloud computing going up up and away [Accessed May 19, 2012].

[4]. Bhushan Lal Sahu,Rajesh Tiwari, Journal of Advanced Research in Computer Science and Software Engineering 2(9) (2012) 33-37.

[5]. U. Oktay, U.\& Sahingoz, O.K.(2013) "Attack Types and Intrusion Detection Systems in Cloud Computing" 6th international information security \& cryptology conference, pp.71-76.

[6]. Security for Cloud Computing 10 Steps to Ensure Success, 2012 Cloud Standards Customer Council

[7]. Pawar A,. ; Shingavi, A.; Pabale, S.; Chahyal G. (2014) "Reliability security for cloud computing" International Journal of Emerging Technology and Advanced Engineering. Vol.4.N0.8, pp.757-759.

[8]. Patrick Höner (2013) "Cloud Computing Security Requirements and Solutions: a Systematic Literature Review" 19thTwente Student Conference on IT, June 24th, 2013, Enschede, The Netherlands.

[9]. Jain A.;Panday, U.S.(2013) "Role of Cloud Computing in Higher Education", International Journal of Advanced Research in Computer Science and Software Engineering. Vol.3, No.7.pp.966-972.

[10]. Bhatia1, G.; Anand, M.; Shrivastava, p. (2012) "Cloud computing technology in education system", International Journal of Advanced Technology \& Engineering Research, Vo.2, No.2, pp.125-128.

[11]. Giriraj, M. \& Muthu,S. (2013) " A cloud computing methodology for industrial automation and manufacturing execution system" Journal of Theoretical and Applied Information Technology. Vol.52.No.3, pp.301-307.

[12]. I. Sriram and K.H. Ali, Research agenda in cloud technologies, 2 February 2010. http://arxiv.org/ftp/arxiv/papers/1001 /1001.3259.pdf

[13]. Verma, R.K. ; Dutta, S. ; Chaulya, S.K. ; Singh, A.K. \& Prasad, G.M. (2013) "Cloud Computing: A New Era in IT industry" International Journal of Computer Technology and Electronics Engineering, Vol.3, No.2, pp.18-28.

[14]. A. I. Aysan, H. Yigit and G. Yilmaz, "GIS application in cloud computing platform and recent advances", Proceedings of 5th International Conference on Recent Advances in Space Technologies, , Istanbul, Turkey, pp. 193-196, June 9-11, 2011. 
[15]. E. A. Minaeva, (2011) "Application of cloud computing in field of power engineering". Proceedings of 3rd International Youth Conference on Energetics, Leiria, Portuga, pp. 1-5, July 9-11, 2011.

[16]. Chunye Gong, Jie Liu, Qiang Zhang, Haitao Chen and Zhenghu Gong (2010) "The Characteristics of Cloud Computing" 2010 39th International Conference on Parallel Processing Workshops, IEEE, Computer society, pp.275-279.

[17]. A. Singh N., V. Vasanthi \& M. Hemalatha, (2012) "A brief survey on architecture, challenges and security benefit in cloud computing", International Journal of Information and Communication Technology Research, vol. 2, pp. 102-111, February 2012.

[18]. Yanxin Zhu, Di Wu \& Sujian Li (2013) "Cloud Computing and Agricultural Development of China: Theory and Practice" International Journal of Computer Science Issues, Vol.10, No.1, pp.7-12.

[19]. Patel, R. \& Patel, M. (2013) "Application of Cloud Computing in Agricultural Development of Rural India", International Journal of Computer Science and Information Technologies, Vol. 4, No.6, pp. 922-926.

[20]. Rani, S. \& Gangal, A. (2012) "security issues of banking adopting the application of cloud computing" International Journal of Information Technology and Knowledge Management, Volume 5, No. 2, pp. 243-246.

[21]. M. Abualkibash and K. Elleithy, "Cloud computing: the future of IT industry", International Journal of Distributed and Parallel 